\title{
Izboljšave modela za dnevno napoved verjetnosti nastanka gozdnega požara v letu 2015
}

\author{
Nikica OGRIS $^{1 *}$, Neva PRISTOV², Tomaž ŠTURM³
}

Vsakodnevno napoved verjetnosti nastanka gozdnega požara pripravljamo na Gozdarskem inštitutu Slovenije že dve leti. Napoved temelji na podlagi izračunov računskega modela, tj. meteorološkega indeksa požarne ogroženosti gozdov (Ogris in Šturm, 2016; slika 1). Številčno oceno verjetnosti nastanka gozdnega požara dobimo s pomočjo šest standardnih komponent indeksa meteorološke požarne ogroženosti. Osnova so tri šifre vlažnosti goriva (šifra vlažnosti drobnega goriva, angl. Fine Fuel Moisture Code - FFMC, šifra vlažnosti srednjega goriva, angl. Duff Moisture Code - DMC, šifra vlažnosti grobega goriva, angl. Drought Code - DC), ki se odzivajo na dnevne spremembe vsebnosti vlage $v$ treh razredih gozdnega goriva $\mathrm{z}$ različnimi stopnjami hitrosti sušenja. Vmesna indeksa širjenja požara predstavljata stopnjo širjenja (indeks začetnega širjenja, angl. Initial Spread Index - ISI) in količino razpoložljivega goriva (indeks celotnega goriva, angl. Build-Up Index - BUI). Končni indeks širjenja požara je indeks FWI (indeks požarne ogroženosti gozdov, angl. Fire Weather Index FWI), ki združuje vmesna dva indeksa in predstavlja intenzivnost širjenja požara. Uporablja se tudi kot splošni indeks požarne ogroženosti.

Vhodni podatki za izračun teh količin so temperatura zraka, relativna zračna vlažnost, hitrost vetra in 24-urna količina padavin (vse ob ob 12. uri). Te podatke dobimo iz napovedi modela ALADIN-SI (slika 2), tj. numeričnega meteorološkega modela za računanje bodočega stanja ozračja nad širšim območjem Slovenije (Pristov in sod., 2012), ki ga uporablja ARSO. Analiza in bodoče 3-dimenzionalno stanje ozračja se izračuna na vsakih 6 ur za naslednjih 72 ur v krajevni ločljivost $4,4 \mathrm{~km}$ nad območjem velikim $1850 \mathrm{~km}$ krat $1850 \mathrm{~km}$. V letu 2015 se je opisani sistem posodobil in nadgradil, izboljšala se je tudi kakovost napovedi. Temu smo prilagodili tudi izračun verjetnosti požarne ogroženosti in z 22.10.2015 smo napoved podaljšali iz dveh na tri dni v naprej.

Vse tri šifre vlažnosti goriva (FFMC, DMC in DC) nastopajo v modelu FWI z vrednostmi prejšnjega dne, ki so bile izračunane na podlagi napovedi modela ALADIN-SI za ta dan. Napovedi pa so obremenjene z napako, najbolj nezanesljive so napovedi konvektivnih padavin, ki se krajevno zelo spreminjajo. Za prejšnji dan imamo na razpolago meritve iz avtomatskih in nekaterih klasičnih postaj državne meteorološke mreže, ki bi jih lahko uporabili za korekcijo modela FWI. Ker pa model potrebuje vhodne podatke nad območjem Slovenije v krajevni ločljivosti, ki je večja ali vsaj enaka ločljivosti modela ALADIN-SI, moramo vrednosti temperature in vlažnosti zraka, hitrosti vetra ter količine padavin določiti v vseh točkah modela FWI. To lahko dosežemo z zapletenimi postopki prostorske interpolacije podatkov (npr. ko-kriging). V našem primeru pa uporabimo kar analizo, ki jo naredijo na ARSO s pomočjo sistema INCA (Integrated Nowcasting through Comprehensive Analysis). Sistem INCA je eden izmed sistemov za izračun zelo kratkoročnih ali zdajšnjih (angl. nowcasting) meteoroloških napovedi $\mathrm{v}$ visoki prostorski in časovni ločljivosti (Haiden in sod., 2011; Šajn Slak in sod., 2012; slika 3). Kot prvi približek stanja ozračja uporabi prostorska polja meteoroloških spremenljivk numeričnega meteorološkega modela ALADIN-SI, nato pa s pomočjo interpolacijskih metod ob upoštevanju določenih fizikalnih zakonitosti izračunava 3-dimenzionalno fizikalno konsistentno analizo v visoki krajevni ločljivosti (1 km), v katero vključuje širok spekter različnih meritev (podatke s klasičnih in avtomatskih meteoroloških postaj, radarske in satelitske podatke in še druge razpoložljive podatke izven državne meteorološke mreže). Ta analiza je nato osnova za izračun nekaterih diagnostičnih polj kot tudi za kratkoročno napoved meteoroloških spremenljivk za 12 ur naprej. Ključno pri tem je, da so izračuni dovolj hitri, da so lahko analize in napovedi dostopne praktično v realnem času ali zelo blizu realnega časa, kar omogoča tudi pogosto obnavljanje napovedi ob dostopnosti novih podatkov. Količina padavin se izračuna vsake pol ure, ostale spremenljivke (temperatura zraka, relativna zračna vlažnost, hitrost in smer vetra) pa vsako uro. V času objave tega članka model FWI uporablja samo analizo podatkov, s katerimi korigiramo tri šifre vlažnosti goriva (FFMC, DMC in DC) za prejšnji dan in tako izboljšamo napoved za naslednje tri dni. Vsaj eno leto bo moralo preteči, da bomo lahko preverili, koliko se je zanesljivost modela FWI izboljšala na račun njegovih izboljšav v letu 2015.

Načrtujemo, da bomo sistem nadgradili s kratkoročno napovedjo širjenja požarov (Van Wagner in sod., 1992), pri katerem bodo kratkoročne napovedi iz sistema INCA (predvsem vetra v visoki krajevni ločljivosti) neobhodne. Predpogoj za razvoj modela za kratkoročno napoved širjenja požarov je kakovostna karta goriv, ki pa za Slovenijo še ni izdelana (Šturm, 2013). Upamo, da bomo s primernim raziskovalnim projektom izdelali manjkajočo karto goriv in tako izpolnili zadnji pogoj za razvoj modela za kratkoročne napovedi širjenja požarov.

\section{Zahvala}

Najlepše se zahvaljujemo ARSO za izjemno obsežno in nesebično sodelovanje ter za pripravo in posredovanje podatkov modela ALADIN-SI in INCA. Članek je nastal v okviru Javne gozdarske službe na Gozdarskem inštitutu Slovenije in Zavoda za gozdove Slovenije, ki ga financira Ministrstvo za kmetijstvo, gozdarstvo in prehrano. 


\section{Viri}

Haiden, T., A. Kann, C. Wittmann, G. Pistotnik, B. Bica, C. Gruber, 2011: The Integrated Nowcasting through Comprehensive Analysis (INCA) system and its validation over the Eastern Alpine region. Weather and Forecasting, 26, 166-183.

Ogris N., Šturm T. 2016. Meteorološki indeks požarne ogroženosti gozdov. Napovedi o zdravju gozdov, http://www.zdravgozd.si/prognoze zapis.aspx?idpor $=6$

Pristov N., Cedilnik J., Jerman J., Strajnar B. 2012. Priprava numerične meteorološke napovedi ALADIN-SI. Vetrnica 4: 17-22; http://www.meteo-drustvo.si/data/upload/Vetrnica 0412.pdf

Računska napoved meteorološkega modela ALADIN/SI. ARSO http://meteo.arso.gov.si/met/sl/app/webmet (3. 2. 2016)

Šajn Slak A., Kršmanc R., Merše J. 2012. INCA-CE - projekt, ki povezuje meteorološke službe osrednje Evrope s končnimi uporabniki. Vetrnica 4: 61-63; http://www.meteo-drustvo.si/data/upload/Vetrnica 0412.pdf

Šturm T. 2013. Uporaba tehnologije GIS za napovedovanje pojavljanja gozdnih požarov v Sloveniji. Doktorska disertacija, Ljubljana,

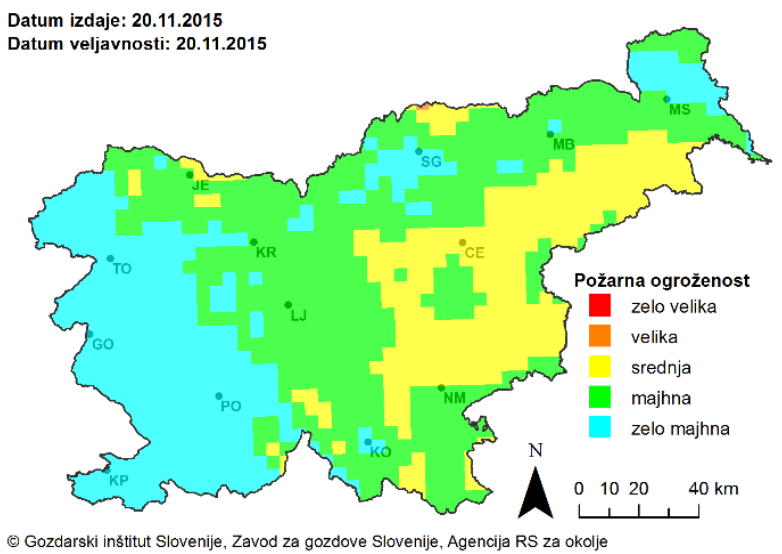

Slika 1: Napoved požarne ogroženosti gozdov na dan 20. 11 . 2015 (Ogris in Šturm, 2016)

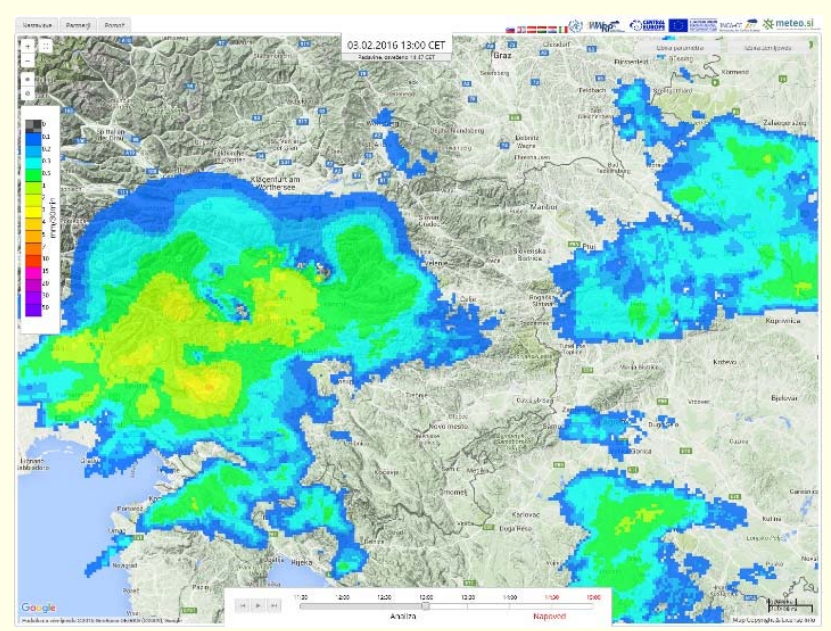

Slika 3: Primer karte padavin iz sistema INCA: analiza in napoved za 3. 2. 2016 ob 13. uri (Trenutno stanje vremena ..., 2016)
Univerza v Ljubljani, Fakulteta za gradbeništvo in geodezijo: 138 str.

Trenutno stanje vremena in zelo kratkoročna avtomatizirana napoved - INCA/SI. ARSO, 2016, http://meteo.arso.gov.si/met/sl/app/inca/ (3. 2. 2016)

Van Wagner C.E., Stocks B.J., Lawson B.D., Alexander M.E., Lynham T.J., McAlpine R.S. 1992. Development and structure of the Canadian forest fire behavior prediction system. Information report, ST-X-3: 1-63.

${ }^{1}$ Gozdarski inštitut Slovenije, Večna pot 2, 1000 Ljubljana; ${ }^{2}$ Agencija RS za okolje, Vojkova 1B, 1000 Ljubljana; ${ }^{3 Z}$ Zavod za gozdove Slovenije, Večna pot 2, 1000 Ljubljana

*nikica.ogris@gozdis.si

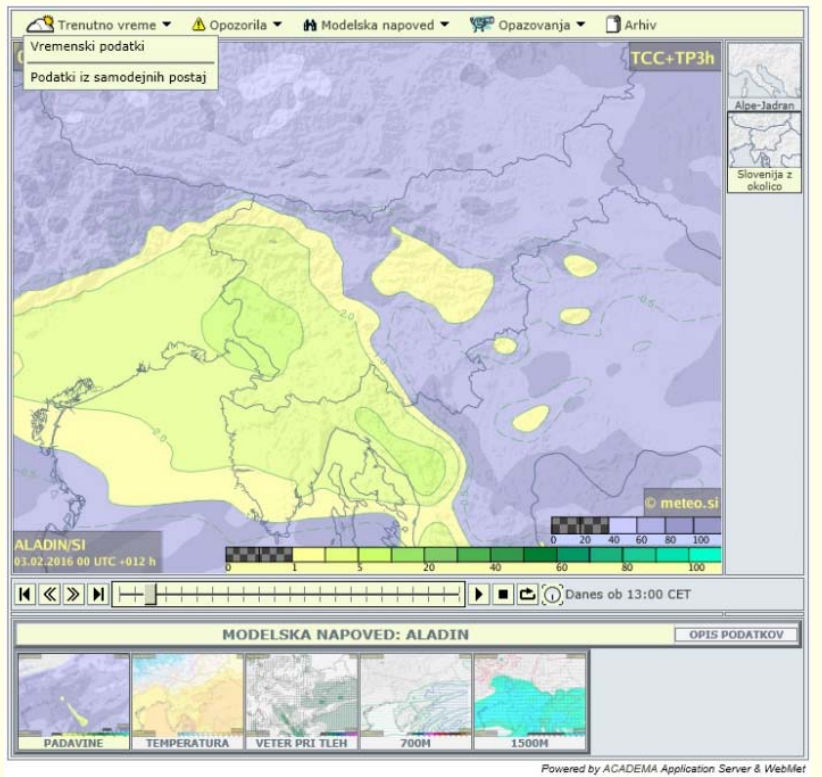

Slika 2: Primer napovedi padavin modela ALADIN-SI za 3. 2. 2016 ob 13. uri (Računska napoved ..., 2016) 